\title{
Rotorcraft Research at the NASA Vertical Motion Simulator
}

\author{
Bimal L. Aponso, ${ }^{1}$ Duc T. Tran, ${ }^{2}$ and Jeffery A. Schroeder ${ }^{3}$ \\ NASA Ames Research Center, Moffett Field, CA 94035
}

In the 1970's the role of the military helicopter evolved to encompass more demanding missions including low-level nap-of-the-earth flight and operation in severely degraded visual environments. The Vertical Motion Simulator (VMS) at the NASA Ames Research Center was built to provide a high-fidelity simulation capability to research new rotorcraft concepts and technologies that could satisfy these mission requirements. The VMS combines a high-fidelity large amplitude motion system with an adaptable simulation environment including interchangeable and configurable cockpits. In almost 30 years of operation, rotorcraft research on the VMS has contributed significantly to the knowledgebase on rotorcraft performance, handling qualities, flight control, and guidance and displays. These contributions have directly benefited current rotorcraft programs and flight safety. The high fidelity motion system in the VMS was also used to research simulation fidelity. This research provided a fundamental understanding of pilot cueing modalities and their effect on simulation fidelity.

\section{Introduction}

In the 1960's, the role of the military helicopter evolved from primarily a utility role to encompass more demanding roles including ground assault transport and ground attack. In the 1970's, low-level nap-of-the-earth (NOE) flight, air-to-air combat, and night operations were added as necessary future capabilities based on experience in recent conflicts. Designing a new generation of rotorcraft to meet these evolving and increasingly demanding missions required a significant expansion of the existing knowledgebase on rotorcraft performance and flying characteristics. Fundamental research was required to investigate and to develop new technologies and rotorcraft designs that could accomplish these more demanding missions with improved safety. The single-main-rotor helicopter was the most common rotorcraft configuration at the time. With unstable dynamics at low-speed and significant cross-coupling between axes of control, the single-rotor helicopter was demanding to fly and required closed-loop pilot control at all times. Expansion of the existing knowledgebase on rotorcraft required a high-fidelity flight simulation environment. This requirement was met at NASA Ames Research Center using a combination of ground-based simulation and in-flight simulation using variable stability research rotorcraft.

For almost four decades, the Vertical Motion Simulator (VMS) and its predecessor, the Flight Simulator for Advanced Aircraft (FSAA) at NASA Ames Research Center, have been cornerstones for rotorcraft research. Built in 1969, the FSAA was originally designed for fixed-wing aircraft research and, as it was increasingly used for rotorcraft research, the need for improved motion fidelity, particularly in the vertical axis, became evident (Ref. 1). The VMS was designed to meet this need and became operational in 1979. The VMS included the highest fidelity motion system in the world, a distinction it holds to this day. In addition to high-fidelity vertical and lateral motion cueing, the VMS included an interchangeable cab system with high-fidelity visual displays of the outside world and adaptable cockpit interfaces with accurate control feel systems, flight instruments and displays.

The need to expand the knowledgebase on rotorcraft performance and flying qualities was recognized by the Army who, in collaboration with NASA, began a program to meet this need. In addition to research on rotorcraft, a parallel and interacting stream of studies examined human pilot cueing and the level of simulation fidelity required to accurately recreate the pilot-rotorcraft interaction in flight. In almost three decades of operation, simulation studies on the VMS by a team of NASA and U.S. Army Aeroflightdynamics Directorate (AFDD) researchers at the Ames Research Center have generated a major share of these data. Jet powered V/STOL aircraft and technologies were also evaluated on the VMS through collaboration between NASA and industry. This paper will focus on rotorcraft and provide an overview of rotorcraft research, and summarize the impact of this work on current and

\footnotetext{
${ }^{1}$ Chief, Aerospace Simulation Operations Branch, bimal.l.aponso@nasa.gov, Associate Fellow.

${ }^{2}$ VMS Facility Manager, Aerospace Simulation Operations Branch, duc.t.tran@nasa.gov, Member.

${ }^{3}$ Chief, Aviation Systems Division, jeffery.a.schroeder@nasa.gov, Associate Fellow.
} 
future rotorcraft design, development, procurement, and operations. The research may be grouped into six streams of rotorcraft research: handling qualities; guidance and displays; simulation fidelity and cueing; flight control design and evaluation, specific programs; and tilt-rotor. Following a description of the present capabilities of the VMS, this paper will summarize the research conducted in each of these streams of research.

\section{Description of the VMS}

The Vertical Motion Simulator (VMS) combines a high-fidelity simulation capability with an adaptable simulation environment that allows the simulator to be customized to a wide variety of human-in-the-loop research applications. The distinctive feature of the VMS is its unparalleled large amplitude, high-fidelity motion capability. The high level of simulation fidelity is achieved by combining this motion fidelity with excellent visual and cockpit interface fidelities. An interchangeable cab arrangement allows different crew vehicle interfaces and vehicle types to be evaluated allowing fast turnaround times between simulation projects. The VMS motion system is a six degree-of-freedom combined electro-mechanical/electro-hydraulic servo system, shown in Figure 1. It is located in and partially supported by a specially constructed $120 \mathrm{ft}$ tower. The motion platform consists of a $40-\mathrm{ft}$ long beam that travels $\pm 30 \mathrm{ft}$ vertically. On top of the beam is a carriage that traverses the $40-\mathrm{ft}$ length of the beam. A sled sits atop the carriage providing the \pm 4 - $\mathrm{ft}$ of travel in a third translational degree of freedom. A conically shaped structure is mounted on the sled and rotates about the vertical axis providing yaw motion. A two-axis gimbal allows pitch and roll motion. The ICAB is attached to the top gimbal ring. The motion capability of the VMS is summarized in the Table 1.

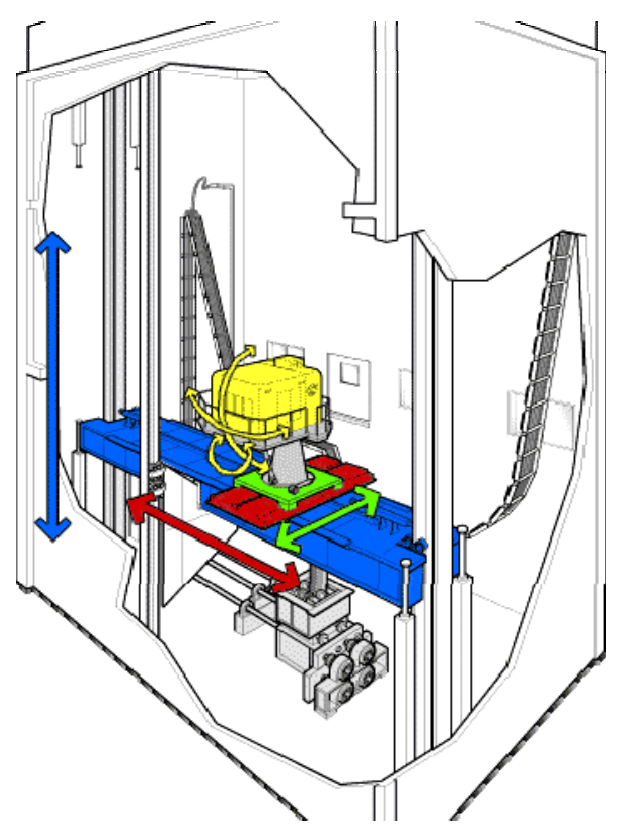

Figure 1. Cutaway Diagram of the VMS Facility

Table 1. VMS motion capability 


\begin{tabular}{|c|c|c|c|}
\hline \multicolumn{4}{|c|}{ VMS NOMINAL OPERATIONAL MOTION LIMITS } \\
\hline Axis & $\begin{array}{c}\text { Displacement } \\
(\mathrm{ft})\end{array}$ & $\begin{array}{c}\text { Velocity } \\
(\mathrm{ft} / \mathrm{sec})\end{array}$ & $\begin{array}{c}\text { Acceleration } \\
\left(\mathrm{ft} / \mathrm{sec}^{\wedge} 2\right)\end{array}$ \\
\hline Vertical & \pm 30 & 16 & 24 \\
Lateral & \pm 20 & 8 & 16 \\
Longitudinal & \pm 4 & 4 & 10 \\
& $(\mathrm{deg})$ & $(\mathrm{deg} / \mathrm{sec})$ & $($ deg/sec 2$)$ \\
Roll & \pm 18 & 40 & 115 \\
Pitch & \pm 18 & 40 & 115 \\
Yaw & \pm 24 & 46 & 115 \\
\hline
\end{tabular}

The Interchangeable Cab (ICAB) capability in the VMS allows the cockpit to be tailored to the research application. The VMS has five portable ICABs with different out-the-window (OTW) visual fields-of-view. For each simulation study, the cab is equipped based on the requirements that simulation and tested fixed-base with the complete simulation environment except for motion. Equipping the cab includes installation of flight controls, flight instruments and displays, and seats (Fig. 2). Following equippage and checkout, the ICAB is transported and installed on the motion system. The ICAB capability allows the VMS facility to conduct fixed-base and moving base simulation studies simultaneously.
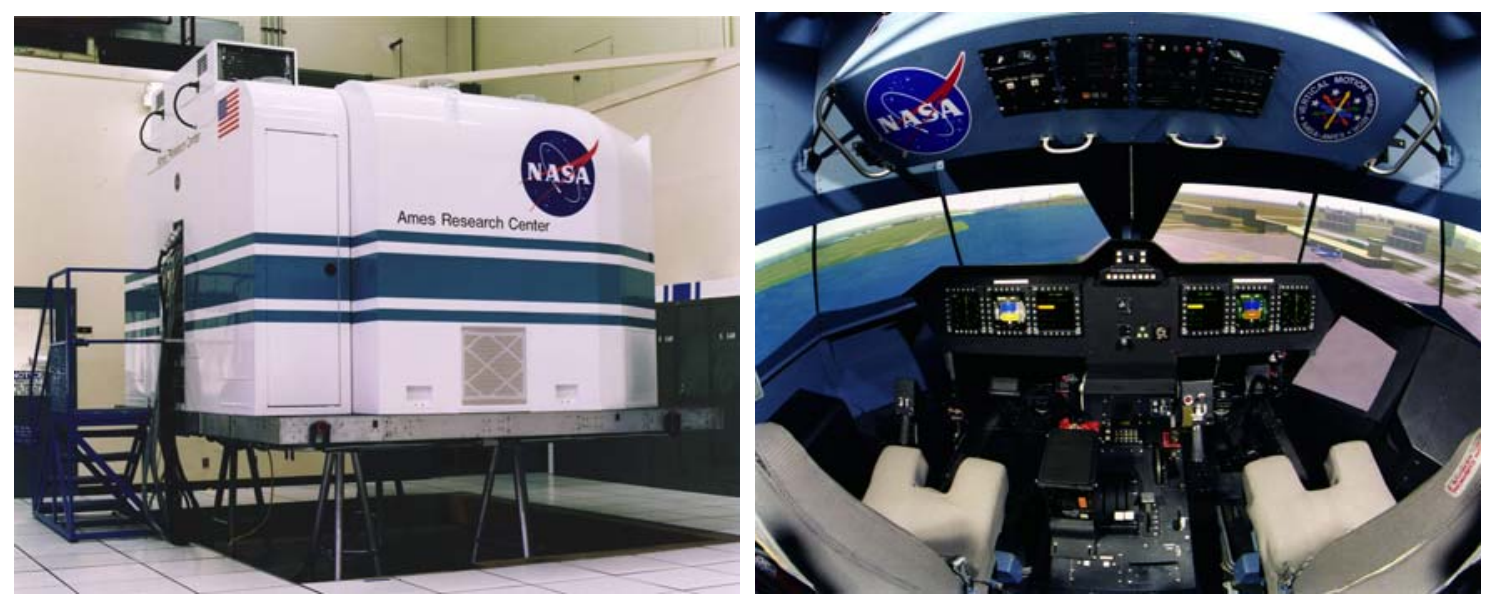

Figure 2. Exterior and interior of Transport Cab (TCAB) with eight out-the-window visual displays

The high-fidelity flight controls are heavily modified and optimized McFadden hydraulic force loader systems (Ref. 2). A digital control interface allows all aspects of the controller's static and dynamic characteristics to be adjusted. It also allows characteristics to be varied in real-time as necessary for researching pilot cueing concepts using controllers. The force loader is available on a variety of aircraft control manipulators from the regular column and wheel type to conventional rotorcraft controls and side sticks.

The out-the-window visual scene is generated by a Rockwell-Collins EPX-5000 image generation (IG) system providing a high-resolution and complex visual environment at fast frame rates (Fig. 3). Presently, capability is for nine channels of IG that will be expanded to 15 this year. This IG capability allows the VMS to operate up to three different simulation experiments at the same time. In-house graphics expertise at the VMS customizes the visual databases to particular simulation requirements. Separate graphics processors generate the displays required for primary flight displays, head-up displays, sensor imagery, etc. These displays may also be customized to the researcher's needs. 

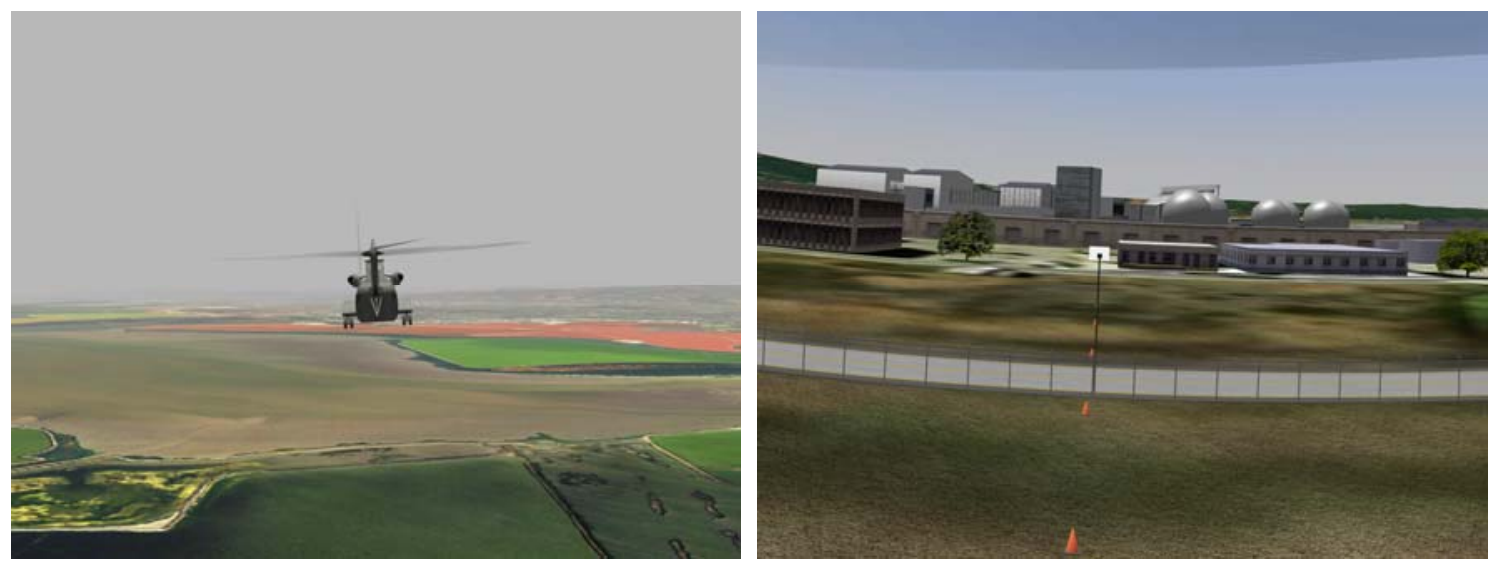

Figure 3. Typical outside visual scenes

All the essential elements of the simulation are linked with the host environment through a dedicated network and controlled through a fully equipped control room. The flexible simulation architecture makes it convenient to interface and to evaluate custom software and hardware modules on the VMS. This capability may be used to evaluate sensors, vehicle dynamic models, flight control systems, etc.

\section{Handling Qualities Studies}

In the 1970's, the Army needed a handling qualities specification that could guide the development of rotorcraft that would meet the more demanding missions and tactics envisioned in the future. The military specification for rotorcraft handling qualities, MIL-H-8501A, was written in 1952 and was inadequate (Ref. 3). Several attempts to update MIL-H-8501A met with little success and were not adopted, primarily due to a lack of background data of adequate quality. To overcome the deficiencies in MIL-H-8501A, the Army used Prime Item Development Specifications (PIDS) for procuring new helicopters (Ref. 3). The U. S. Army Aeroflightdynamics Directorate (AFDD), in collaboration with NASA Ames Research Center, began an effort to build a database of handling qualities data and design criteria that could be incorporated into a new handling qualities specification. In 1982, the AFDD began the development of a new rotorcraft handling qualities specification to supersede MIL-H-8501A (Ref. 3). The specification, US Army Aeronautical Design Standard - 33 or ADS-33 (Ref. 4), was completed and published in 1987. Initial development of the specification was for the procurement of the modern light/attack/scout helicopter (LHX) the Army intended to acquire. This program led to the development of a prototype helicopter, the RAH-66 Comanche.

The strategy for developing a helicopter handling qualities database of sufficient quality and validity for use in a military specification was to combine high-fidelity simulation with a limited amount of flight test activity. Almost all the simulation data incorporated into ADS-33 came from VMS studies. The process of developing the database is ongoing, and several simulation studies in 2008 will fill known gaps in the database and refine others. Table 2 lists the VMS simulation studies that have supported this process.

Reference 1 contains a comprehensive summary of the rotorcraft research conducted in the VMS in its first decade of operation. Initial studies focused on two issues of primary concern: 1) rotorcraft design requirements for lowaltitude or nap-of-the-earth (NOE) flight, and 2) flight in adverse visual conditions. Not all these studies were documented or published, but their data were used to develop criteria in ADS-33 and are available in the Background Information and Users Guide to ADS-33 (Ref. 4).

Initial studies investigated the effect of design variations on rotorcraft dynamic characteristics and handling qualities. These included the effect of vertical damping and thrust available (Ref. 5), pitch/roll and collective/yaw cross coupling (Refs. 6 and 7), yaw control (Refs. 8 and 9), and roll control (Ref. 10). Other studies investigated some of the fundamental precepts under development for the specification - required response type and bandwidth. An innovative concept introduced in ADS-33 is the trade-off between augmentation (which defines response type) and the visual cueing environment. Ground-based and in-flight simulation studies established that when the visual cueing environment is degraded, increased compensation is required to maintain handling qualities at a satisfactory

4

American Institute of Aeronautics and Astronautics 
level. Bandwidth is a measure that defines the quickness in the response to control inputs and represented a shift, at the time, from time-domain based performance criteria to a more accurate and discriminating frequency-domain measure. Studies on the VMS that developed these concepts include those reported in Refs. 11, 12, and 13.

Table 2. Rotorcraft handling qualities simulation studies

\begin{tabular}{|cc|}
\hline Simulation Description & Year(s) \\
Heavy-Lift Rotorcraft (HLR) stability margin/handling qualities & 2008 \\
Handling qualities with external slung loads (8 simulations) & $1994-2008$ \\
Civil handling qualities specification & 2001 \\
LHX/RAH 66 handling qualities & (4 simulations) \\
Helicopter cross-coupling studies & (3 simulations) \\
Handling qualities for helicopter air combat (6 simulations) & $1982-1992$ \\
Handling qualities for yaw control & $1986-1994$ \\
Handling qualities for roll control & (2 simulations) \\
Single/dual pilot advanced cockpit and handling qualities (2 simulations) & $1984-1992$ \\
Handling qualities for shipboard landing & 1984 \\
Handling qualities for vertical control & 1984,1985 \\
Effect of rotorcraft design on handling qualities (3 simulations) & 1986 \\
\hline
\end{tabular}

Several studies by the AFDD also investigated helicopter and flight control system design requirements for aggressive air-to-air combat (Refs. 14, 15, and 16) at low-altitude. These studies provided data on the effect of response type, pitch/roll/yaw bandwidth, and turn coordination on handling qualities when the rotorcraft itself is used as a pointing platform. Another study investigated the yaw dynamic requirements for a rotorcraft with a turreted gun engaged in low-level air combat operations (Ref. 17). The study investigated the potential trade-off between gun slewing angular movement capability and required rotorcraft yaw axis response. A separate series of studies investigated the handling qualities and cockpit interface that would be required for single-pilot operation envisioned, at that time, for the LHX program (Ref. 18). These studies indicated that the mission management and demanding NOE flight environment placed an unacceptable workload on a single pilot that may be alleviated by increasing augmentation through the flight control system.

An important outcome of these studies was the progressive development of evaluation tasks that were designed to be representative of the mission tasks expected of rotorcraft but also constrained to allow repeatability and promote consistency in handling qualities ratings. These evaluation tasks, or Mission Task Elements (MTEs), were refined over the course of many experiments on the VMS and included in ADS-33 as demonstration maneuvers for evaluating the overall handling qualities of a rotorcraft. Task performance displays for the MTEs were also developed over the course of many experiments on the VMS and these displays have transitioned to flight testing.

Finally, a series of eight simulation studies investigated the effect of externally slung loads on helicopter handling qualities. The results of the first five simulation studies by the AFDD are reported in Ref. 19. These simulation studies established a database of handling qualities data for future inclusion in ADS-33 as guidelines for the design of rotorcraft that carry external loads. The database on handling qualities is being further expanded by follow-on simulation studies on the VMS that will explore heavy cargo rotorcraft operations including the effect of pitch/roll response-type on handling qualities with slung loads. 
Since its release, ADS-33 has guided the procurement of the $\mathrm{CH}-47 \mathrm{~F}$ and $\mathrm{CH}-53 \mathrm{~K}$ helicopters, and the UH-60Mu and AH-64D fly-by-wire upgrades by the Army and Navy. It was designed for and used as the guiding specification for the RAH-66 Comanche flight control system that is the basis for the full-authority fly-by-wire flight control systems implemented on the UH-60Mu, CH-53K, H-92 Superhawk, and the digital automatic flight control system (DAFCS) on the CH-47F. The CH-47F flight control system was evaluated on the VMS. The RAH-66 control system design was, in turn, based on extensive research on the Army's advanced digital optical control system (ADOCS) program that also used the VMS for initial design and development.

\section{Flight Control Design Studies}

Table 3 lists the VMS simulation studies that evaluated flight control system concepts and designs. All these development efforts were closely linked with the development of a handling qualities knowledgebase. To evaluate new flight control concepts in preparation for the procurement of a new attack helicopter (LHX), the Army initiated the ADOCS program to investigate modern flight control system concepts and pilot-vehicle interfaces. A series of simulation studies on the VMS evaluated modern control laws, flight control system architectures, and cockpit interface concepts including multi-axis side sticks and advanced pilot displays (Ref. 20). Outcomes of these studies were recommendations for the design of multiaxis pilot controllers, flight control system designs with advanced response types; control law mode switching logic; automatic stick force trimming; and helmet mounted display. These concepts were implemented and flight-tested on the ADOCS UH-60 helicopter. The designs translated well from simulation to flight and only minor parametric changes were required in flight to optimize handling qualities (Ref. 21). The program provided invaluable data on advanced flight control system design. The fundamental flight control concepts and architectures developed in the program have influenced all the rotorcraft fly-by-wire flight control systems designed since that time.

Table 3. Flight control systems research simulations

\begin{tabular}{|cc|}
\hline Simulation Description & Year(s) \\
CH-47F digital automatic flight control system (2 simulations) & $2004-2005$ \\
UH-60 MCLAWS evaluation & 2002 \\
Partial authority flight control systems (4 simulations) & $1991-1998$ \\
Advanced Digital Optical Control System (ADOCS) program \\
(4 simulations)
\end{tabular}

The difficulty of landing rotorcraft in blowing sand, known as brownout, became evident in the first Gulf War. Conducting operations under cover of darkness using night vision goggles (NVG) was also becoming more prevalent as the quality of the devices improved. At that time, the knowledgebase on rotorcraft handling qualities included significant evidence that control augmentation could alleviate handling qualities deficiencies in degraded visual environments such as brownout and NVGs. A series of simulation studies on the VMS investigated the possibility of modifying the existing limited authority flight control system on the UH-60 Black Hawk to provide added augmentation to improve handling qualities when flying in degraded visual environments (Refs. 22 - 24). The simulation studies explored different methods for adding this increased augmentation using the existing flight control system mechanization and evaluated the effect of saturating the stability augmentation system for larger pilot inputs. Based on the favorable results of these studies, increased augmentation was proposed for the Black Hawk and tested on the VMS (Ref. 25).

The CH-47F with its digital automatic flight control system (DAFCS) was the first production Army helicopter to be acquired using ADS-33 requirements. The DAFCS included advanced response types to improve handing qualities in degraded visual environments. Following development and initial testing by the manufacturer, they were refined and evaluated by Army pilots in an AFDD conducted simulation study on the VMS (Ref. 26). The simulation investigations showed that the DAFCS significantly improved handling qualities in day and night (using NVGs) 
visual conditions when compared with a CH-47D. Transitions between response type modes in the DAFCS were also improved based on the findings of VMS simulation study.

\section{Studies on Specific Rotorcraft Programs}

The high-fidelity simulation capability of the VMS has been used to evaluate and test new rotorcraft concepts and configurations such as tilt-wing and tilt-rotor as well as to support existing programs such as Comanche and Apache by implementing and evaluating simulation models (Ref. 27). Table 4 lists the simulation studies that fall in this category.

Table 4. Simulation studies supporting specific rotorcraft programs

\begin{tabular}{|cc|}
\hline Simulation Description & Year(s) \\
RASCAL safety systems (3 simulations) & $1989-2008$ \\
Joint Shipboard Helicopter Integration Process (JSHIP) (2 simulations) & $2000-2001$ \\
RAH-66 Comanche & 1997 \\
Tilt-Wing/Advanced Theater Transport (ATT) (4 simulations) & $1991-2002$ \\
Variable Diameter Tilt Rotor (VDTR) & $1988-1993$ \\
AH-64 Apache (4 simulations) & $1991-1993$ \\
Piasecki VTCAD (2 simulations) & $1984-1987$ \\
X-Wing/RSRA (4 simulations) & 1982 \\
\hline
\end{tabular}

Two simulation studies were conducted under the Dynamic Interface Modeling and Simulation System as part of the Joint Shipboard Helicopter Integration Process (JSHIP), sponsored by the Office of the Secretary of Defense, to investigate the simulation fidelity required to accurately recreate the shipboard-landing task (Ref. 28). Considerable effort was placed on achieving the visual and dynamic fidelity required to ensure that the pilot workload was consistent with that experienced in the actual task. The modeling and simulation of the ship airwake and its interaction with the rotorcraft was a particular technical challenge. This study was preceded almost two decades earlier by a similar one that evaluated whether high-fidelity simulation could be used for assessing the shipboard landing environment using the VMS and a model of a SH-2F helicopter (Ref. 29).

Other programs include several unique rotorcraft configurations including a tilt-wing, X-wing, and the Piasecki Vectored Thrust Combat Agility Design (VTCAD). The tilt-wing studies ranged over a period of 10 years and investigated novel control methods such as the geared flap, that were necessary to control the aircraft during wing tilt (Ref. 30), and the effect of augmentation on handling qualities during approach and landing (Ref. 31). The VTCAD concept involved the addition of a ducted fan with thrust vectoring capability in lieu of a tail rotor on an AH-64 helicopter to increase its speed and agility. The AFDD evaluated the efficacy of this design in two VMS investigations.

The X-wing program was a joint Army/NASA project to investigate high-speed rotorcraft that culminated in the development of the prototype Rotor Systems Research Aircraft (RSRA) to test rotor and propulsion concepts. The complex fly-by-wire flight control system for the X-wing required control transitions as the aircraft transitioned from a rotorcraft to a fixed-wing aircraft (Ref. 32). These control laws were refined and evaluated on the VMS.

A joint NASA/Sikorsky study on the VMS compared Sikorsky's Variable Diameter Tilt Rotor (VDTR) concept with a conventional fixed diameter tilt-rotor (Ref. 33). Pilots from government and industry evaluated the VDTR in 
regular and emergency (engine failure) operations. The study demonstrated the enhanced performance potential of the VDTR and identified areas for further study.

Several simulation studies also supported the initial development of the Army/NASA Rotorcraft variable stability Black Hawk known as the Rotorcraft Aircrew Systems Concepts Airborne Laboratory (RASCAL). RASCAL is operated by the U.S. Army's Aeroflightdynamics Directorate. A particular concern during development was controllability of the helicopter if there was a failure in the research flight control system that operated in parallel with the production flight control system. Several studies investigated and quantified the effect of failure transients and assessed the handling qualities following a failure (Ref. 34) and evaluated RASCAL safety systems. A pilot failure rating scale was developed to assess the safety and handling qualities requirements associated with dynamic failures that could occur on a full-authority flight control system as envisioned for RASCAL (Ref. 35). Recent studies on the VMS have focused on modifying the RASCAL safety systems to allow flight testing at lower altitudes.

\section{Simulation Fidelity Studies}

A host of experiments aimed at understanding simulation fidelity requirements for helicopters have been performed on the VMS since its inception including those listed in Table 5. Since the VMS represented the most capable simulator in the world, the first natural question to ask was how good is it compared to flight. While answering critical questions necessary for advancing simulation-based flight training, the results of these studies were also fundamental to the validity of the studies conducted in the other streams of research outlined in this paper.

The first attempt to compare how well the VMS could simulate helicopter flight was conducted cooperatively among several organizations (Ref. 36). Pilot opinion (HQRs) were Level 1 in flight but Level 2 in simulation. These differences led to investigations to improve the rotor model, servo dynamics, and engine. Improvements to the math model, visual systems, motion configurations, and experimental tasks and protocols led to experiments documented in Ref. 37. This experiment compared performance and pilot opinion using a UH-60 operated out of NASA Ames. Extensive frequency-domain identification compared the simulation performance with flight, with the conclusion that the model was a reasonable representation of the flight vehicle. This was an improvement from the 1984 simulation study but deficiencies in visual and heave motion fidelity were noted.

Table 5. Simulation fidelity research

\begin{tabular}{|cc|}
\hline Simulation Description & Year(s) \\
Visual scene height perception - PsychoPath (2 simulations) & $2001-2006$ \\
Autorotation Cues - AutoCue & (2 simulations) \\
Computation situational awareness model -- SAMSIM & $2000-2001$ \\
Simulation fidelity requirements & 2000 \\
(7 simulations) & $1996-1999$ \\
Motion and visual evaluation - MOTIVE & 1993 \\
Simulation validation - SIMVAL & (3 simulations) \\
Visual/motion synchronization - VISMOSYNC (2 simulations) & $1990-1993$ \\
Visual and motion delay - SIMVAC & $1990-1992$ \\
Blackhawk validation & 1992 \\
Simulator sickness study & 1989 \\
Helicopter autorotation (2 simulations) & 1989 \\
\hline
\end{tabular}


Early research on the VMS showed how far away the simulated cues in a typical helicopter are from the real world (Ref. 38) and exposed the need for systematic investigations with objective measures to determine fidelity requirements. Early emphasis was on the relative timing between the visual and motion cues that was a suspected cause of simulator sickness. Using four different motion conditions, McCauley (Ref. 39) found that simulator sickness increased with both time and the level of maneuvering. Using a UH-60 model, Sharkey (Ref. 40) subsequently found that false motion cues had an adverse effect similar to having no motion cues at all.

The effects of asynchrony in the motion and visual cues were also investigated for handling qualities effects. Mitchell and Hart (Ref. 41) examined variations in visual time delays and motion washout filters. They suggested tailoring the motion system to the task and minimizing the mismatch between motion and visual delays. Chung and Schroeder (Ref. 42) studied the motion and visual synchrony among roll, and lateral axes using a predominantly lateral axis task and recommended that the equivalent time delay mismatch between the roll and lateral motion cues not exceed $40 \mathrm{msec}$. Their work also suggested that the equivalent delays in the motion cuing could exceed the equivalent visual delay without a resulting degradation in handling qualities ratings.

When simulating motion in a ground-based simulator where motion displacement is limited, there is a necessary trade-off between the desired initial, or short-term acceleration and the desired sustaining, or long-term, acceleration. Mitchell (Ref. 43) showed that the addition of motion improved pilot opinion ranging from $1 / 2$ to 2 HQR points. For precision tasks, sustained acceleration cues were preferred (reduced washout natural frequencies of the motion filter), while, for aggressive tasks, short-term acceleration cues were preferred.

Schroeder (Ref. 44) used pilot describing function measurements to examine a variety of motion gains and motion washout filter variations on a classical single-axis compensatory tracking task. The results showed that motion cues allowed the pilot to generate lead compensation and improve target tracking phase margins with increasing filter gain or decreased natural frequency. The study also showed no effects for any of the pure yaw motion configurations, which led to subsequent investigations.

To help answer the question on what characteristics a motion filter should have so that simulation is a reasonable representation of flight, Schroeder (Ref. 45) evaluated the proposed Sinacori motion fidelity criteria. Objective and subjective results showed that the original criteria could be relaxed, and these criteria are still used today as a guide when configuring the VMS motion system.

A question that often arises when configuring the motion system is the level of fidelity required in each axis. Specifically, the earlier study that showed little effect of yaw cueing led to a more detailed study (Ref. 46). This study evaluated a helicopter in a single degree of freedom hovering yaw task. Four variations in the motion cueing were studied: full motion, only lateral translational motion, only yaw rotational motion, and no motion. The study found that the lateral acceleration cue was of predominant importance in both performance and opinion. This suggested that if you had strong lateral translational cues, then the yaw rotational cues might be redundant and unnecessary.

In a study that considered visual cueing aspects as well as motion, Johnson (Ref. 47) investigated how the displayed level-of-detail changes as one gets closer or further away from an object for a height control task. The results showed that changing the level-of-detail to maintain constant optical density as the altitude changed, like that of the real world, improved altitude awareness. Texture at this time was only beginning to be used in the VMS. Separately, adding platform motion improved speed regulation and altitude perception. Further systematic changes in visual scene, via changing spatial frequency with alternating black-and-white stripes, and motion cues were evaluated in the vertical axis (Ref. 48). The variations in visual scene evaluated had no effect, while the motion configurations did have an effect. These configurations were subsequently analyzed using a structural pilot model (Ref. 49). The intent was to develop and calibrate a model that would predict pilot opinion for a given rotorcraft and task, and the model's predictions correlated well, in a ranking sense, with the subjective ratings.

The VMS was used to evaluate cueing effects on autorotation in two studies separated by more than a decade (Refs. 50 and 51). In the first study, autorotation task performance decreased with degraded motion cues, yet acceptable performance could be attained as long as there were adequate visual cues. In the second study with improved visual cueing technology, the effect of visual texture and motion variations on autorotation task performance was evaluated. Visual texture affected all measures, but the finest texture did not perform the best, debunking a myth that more texture is better. This result was also supported by a fixed-base psychophysics study (Ref. 52). Visual detail affected only pilot subjective opinion. Pilot performance as well as opinion of motion fidelity improved with increased motion cueing. 


\section{Guidance and Display Studies}

The high-level of motion and cockpit fidelity offered by the VMS made it an ideal platform to assess and prototype rotorcraft guidance and display concepts (Table 6). Early studies on the VMS evaluated the rotorcraft handling characteristics necessary for low-level nap-of-the-earth missions envisioned for the next generation of military rotorcraft. These studies showed that the workload for such missions was unacceptable for a single pilot. A series of studies over several years beginning in 1988 conducted research to develop an automated helicopter flight capability for potential application in the U.S. Army light, attack, scout helicopter (LHX) program (Fig. 4). Several simulation studies on the VMS developed and refined the critical components of a guidance system for terrain and obstacle detection, path prediction, guidance displays and symbology, and automatic control concepts for terrain following/terrain avoidance (TF/TA) (Refs. 53, 54, and 55). The resulting guidance system was implemented on the Army's UH-60 System Testbed for Avionics Research (STAR) and tested in flight. The outcome of the project included several fundamental concepts for displaying flight information superimposed on sensor imagery.

Another series of studies by the AFDD investigated methods for predicting helicopter maneuver limits and communicating this information to the pilot via tactile cueing through the pilot inceptor (Ref. 56). The results showed that tactile cueing through a conventional inceptor or a sidestick enabled the pilots to easily track helicopter structural and power-train limits and avoid exceedances while maneuvering aggressively without referring to flight instruments. The cueing allowed the pilots to extract maximum maneuvering performance from the helicopter without risk of damage. This technology was developed for evaluation on an AH-64 Apache helicopter under the Army’s Helicopter Active Control Technology program (Ref. 57).

Table 6. Research into guidance and display concepts

\begin{tabular}{|c|c|}
\hline Simulation Description & Year(s) \\
\hline Brownout symbology simulation & 2007 \\
\hline Manned-unmanned Teaming - MUT & 2007 \\
\hline Comanche HMD & 2002 \\
\hline Helicopter maneuver envelope enhancement (5 simulations) & $1996-1997$ \\
\hline $\begin{array}{c}\text { Technical control panel - TTCP } \\
\text { (2 simulations) }\end{array}$ & 1993 \\
\hline $\begin{array}{l}\text { Automated nap-of-the-earth - ANOE } \\
\text { (4 simulations) }\end{array}$ & $1989-1996$ \\
\hline $\begin{array}{c}\text { Cat A terminal area procedures } \\
\text { (2 simulations) }\end{array}$ & $1994-1995$ \\
\hline Terrain following/terrain avoidance - TFTA (4 simulations) & $1988-1992$ \\
\hline HUD-3D, ESPNVS, flight symbology & $1989-1991$ \\
\hline
\end{tabular}

The increased operation of helicopters in urban areas brought with it the risk of an accident, particularly in an emergency situation such as an engine failure. Updated procedures for recovering from an engine failure when taking off or landing in confined areas were needed. Two simulation studies on the VMS by NASA and the FAA investigated methods to reduce pilot workload and increase safety for rotorcraft terminal area operations (Ref. 58). The studies examined the benefits of optimal procedures, cockpit displays, and alternate cueing methods for safe terminal area procedures with one-engine inoperative. Results showed that an integrated display reduced pilot workload and improved safety when compared with conventional instruments. 

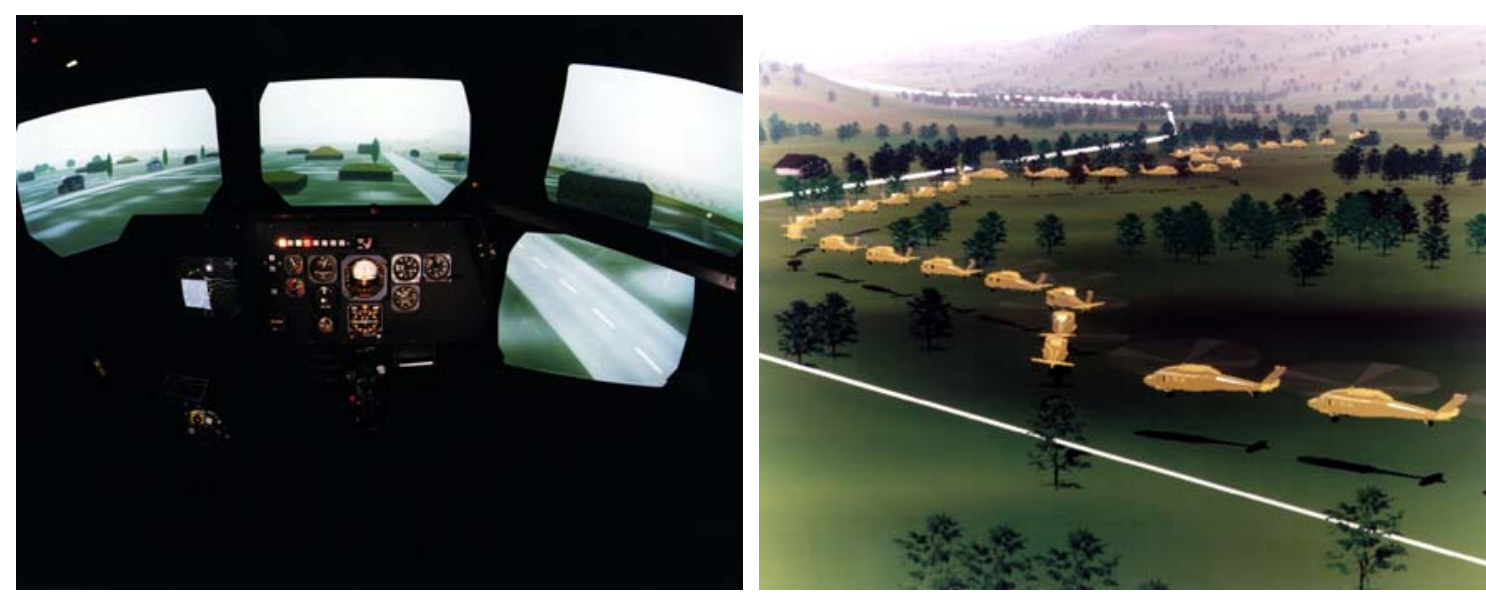

Figure 4. Automated NOE cockpit and test course

In the area of head-mounted displays, a study on the VMS investigated the handling qualities benefits that could be attained using new display law design methods for hover displays (Ref. 59). The display law design was applied to the Apache helmet-mounted display format, using the Apache vehicle dynamics to tailor the dynamics of the velocity predictor symbol. The new symbol dynamics improved the pilots' ability to maneuver about hover in poor visual cuing environments and improved pilot opinion. More recently, the AFDD conducted a simulation study to examine the performance of the Comanche Contact Analog world-referenced symbology displayed on the Comanche's helmet-mounted display when compared with a compressed symbology design similar to that specified by the former MIL-STD-1295 (Ref. 60). Pilot opinion showed a preference for the MIL-STD-1295 symbology. Specific improvements to the Contact Analog symbology were recommended. Another AFDD study, reported in Ref. 61, examined ways to optimize the alerting effectiveness of helmet display symbology. The research investigated two approaches to increasing the effectiveness of alerts - using the entire display surface and including information about the required response in the alert itself. Helmet display symbology was based on the AH-64's pilot night vision system (PNVS), cruise mode symbology. The data showed a small benefit from both the fullscreen alert and the partial information alert.

\section{Tilt-Rotor Studies}

In 1981 the Deputy Secretary of Defense directed that the services reviewed V/STOL technology with the intent of establishing a joint rotary wing aircraft development program to satisfy service lift requirements for medium lift V/STOL aircraft in the 1990s and beyond. This would take advantage of the advanced, but mature, tilt-rotor technology already in place by the early 1970s. The joint NASA/Army XV-15 Tilt-Rotor Research Aircraft program had already begun in the early 1970's and became the foundation for the full-scale development of the JVX, later designated as the V-22 Osprey. A number of simulation studies conducted at the VMS from 1980 to 1985 validated the JVX math model and evaluated the flight control system characteristics. Previous studies on the FSAA had led to the evaluation and selection of Bell to build the XV-15 prototype.

The continued development and flight-testing of the military V-22 Osprey prepared the way for the introduction of a civil tilt-rotor transport. The potential introduction of a civil tilt-rotor transport into the National Airspace System presented challenges and opportunities for vertical flight solutions to airspace congestion. The Federal Aviation Administration (FAA) had developed a Vertiport design guide based on helicopter capabilities and projected civil tilt-rotor transport performance. As a complement to the FAA guide, NASA undertook an effort to develop controls and display technology to fully utilize the capability of this rotorcraft. This effort took the form of a series of ten piloted simulation studies conducted at the VMS (from 1988 to 2001) to investigate tilt-rotor terminal operations and certification issues (Fig. 5). The general objectives of these simulation studies were: 1) to develop design guidance for safe, all-weather, low-noise flight operations, 2) to develop controls and cockpit displays to support tiltrotor transport operations, and 3) to develop tilt-rotor transport terminal area procedures. All these objectives were met. 
Initial studies evaluated steep instrument (IFR) approaches to confined spaces. These steep approaches would reduce the required obstruction-free approach zone and could significantly reduce the noise footprint of terminal operations. Two display concepts were investigated to provide guidance for steep IFR approaches (Refs. 62 and 63). Glide slopes ranging from the nominal 3-degrees up to 25-degrees were investigated. The next series of experiments further evaluated these steep IFR approaches under One-Engine-Inoperative (OEI) conditions. This was followed by handling qualities evaluations of noise abatement landing approaches and comparing them with acoustic measurements from flight tests using the XV-15 aircraft flying similar trajectories (Ref. 64). A potential two-segment approach with initial deceleration at a three-degree glide slope converting to final approach along a nine-degree glide slope was also investigated. The final experiments were full mission simulation studies that evaluated operation in congested airspace and led to the development and use of pursuit displays, particularly for the transition from the airplane type cruise configuration to the helicopter configuration for final approach and landing (Refs. 65 and 66).

In contrast, a study for the Marine Corps, NASA evaluated the effectiveness of the V-22 Osprey tilt-rotor in one-onone air combat maneuvering on the VMS (Ref. 67). The study showed that the unique speed and maneuvering characteristics of the V-22 enhanced its survivability against both fixed-wing and rotorcraft aggressors.

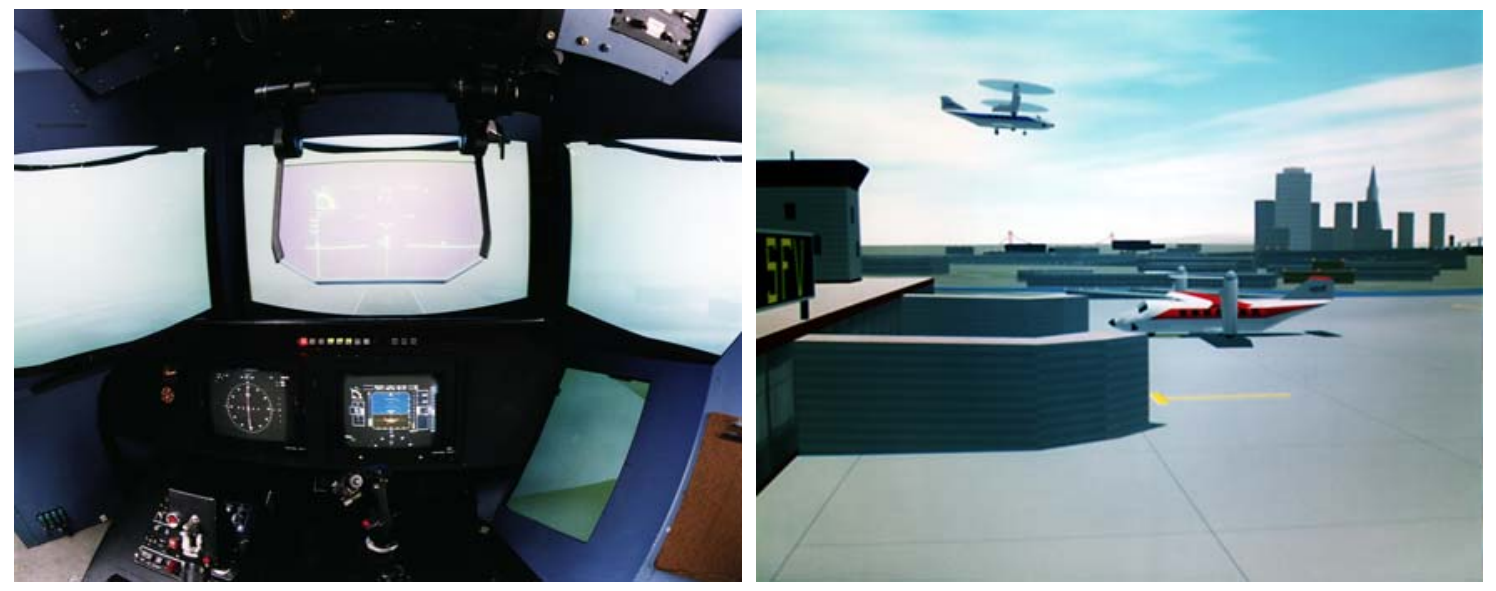

Figure 5. Civil tilt-rotor cockpit (with HUD) and typical visual scene

\section{Concluding Remarks}

Over the past three decades, the NASA Vertical Motion Simulator has provided a wealth of data and knowledge to further rotorcraft technology and safety. The collaboration between NASA and the Army Aeroflightdynamics Directorate at the Ames Research Center has been, and continues to be, a primary reason for the prolific output of valuable research from this facility. This collaboration has developed a database of knowledge on a variety of interacting disciplines on rotorcraft including handling qualities, simulation fidelity, guidance and displays, and design. This database is now used in military procurement and in civil applications on training simulation and guidance displays. NASA programs as well as those in collaboration with the FAA have also contributed significantly to the development of the tilt-rotor aircraft and its civil derivative. Specific contributions include:

- Data on rotorcraft handling qualities that formed a basis for the current military specification on rotorcraft handling qualities, ADS-33E;

- Understanding on human motion and visual cueing, and developing guidelines for configuring simulation cueing environments;

- Designing and evaluating novel rotorcraft configurations including the tilt-wing and tilt-rotor

- Designing and evaluating production flight control systems including the CH-47F;

- Designing and evaluating rotorcraft guidance and display concepts for low-level terrain following and helmet-mounted displays; and

- Civil tilt rotor operation and certification. 


\section{References}

1. Aiken, E. W., Lebacqz, V. J., Chen, R. T., and Key, D. L., "Rotorcraft Handling-Qualities Design Criteria Development," NASA/Army Rotorcraft Technology. Volume 2: Materials and Structures, Propulsion and Drive Systems, Flight Dynamics and Control, and Acoustics, SEE N88-16632 09-01; NASA, Washington, 1988, p 948-998.

2. Mueller, R. A., and Hardy, G. H., "Pilot Force Measurement with Inertia and Gravity Compensation," AIAA Paper 2007-6563, AIAA Modeling and Simulation Technologies Conference, Hilton Head, SC, Aug. 2007.

3. Key, D. L., "Handling Qualities Specifications for U.S. Military Helicopters," AIAA Journal of Aircraft, Vol. 19, no. 2, Feb. 1982.

4. Anon., "Handling Qualities Requirements for Military Rotorcraft," Aeronautical Design Standard—33 (ADS-33E-PRF), US Army Aviation and Missile Command, Mar. 2000.

5. Corliss, L. D., Blanken, C. L., and Nelson, K., "Effects of Rotor Inertia and RPM Control on Helicopter Handling Qualities,” AIAA Paper 1983-2070, AIAA Atmospheric Flight Mechanics Conference, Gatlinburg, TN, Aug. 1983.

6. Watson, D. C., and Aiken, E. W., "An Investigation of the Effects of Pitch-Roll Cross Coupling on Helicopter Handling Qualities for Terrain Flight,” AIAA Conference on Guidance, Navigation, and Control, Monterey, CA., Aug. 1987.

7. Blanken, C. L., Pausder, H. J., and Ockier, C. J., "An Investigation of the Effects of Pitch-Roll (De)coupling on Helicopter Handling Qualities,” NASA-TM-110349, May 1995.

8. Bivens, C. C., and Guercio, J. G., "A Simulation Investigation of Scout/Attack Helicopter Directional Control Requirements for Hover and Low-Speed Tasks,” NASA-TM-86755, Mar. 1987.

9. Whalley, M. S., "A Piloted Simulation Investigation of Yaw Attitude Quickness in Hover and Yaw Bandwidth in Forward Flight,” NASA TM-103948, Sep. 1992.

10. Heffley, R. K., Bourne, S. M., Curtiss, H. C., Jr., Hindson, W. S., and Hess, R. A., "Study of Helicopter Roll Control Effectiveness Criteria; Final Report,” NASA-CR-177404, Apr. 1986.

11. Blanken, C. L., Hart, D. C., and Hoh, R. H., "Helicopter Control Response Types for Hover and LowSpeed Near-Earth Tasks in Degraded Visual Conditions," AHS 47th Annual Forum, Phoenix, AZ, May 1991.

12. Blanken, C. L., Bivens, C. C., and Whalley, M. S., " An Investigation of the Use of Bandwidth Criteria for Rotorcraft Handling Qualities Specifications,” AHS International Conference on Rotorcraft Basic Research, Research Triangle Park, NC, Feb. 1985.

13. Pausder, Heinz-Juergen, and Blanken, C. L., "Investigation of the Effects of Bandwidth and Time Delay on Helicopter Roll-Axis Handling Qualities,” NASA Ames Research Center, Piloting Vertical Flight Aircraft: A Conference on Flying Qualities and Human Factors (SEE N94-13294 02-08), Jul.1993, p 91-110.

14. Lewis, M. S., and Aiken, E. W., "Piloted Simulation of One-on-One Helicopter Air Combat at NOE Flight Levels,” NASA-TM-86686, Apr. 1985.

15. Lewis, M. S., Mansur, M. H., and Chen, R. T., "A Piloted Simulation of Helicopter Air Combat to Investigate Effects of Variations in Selected Performance and Control Response Characteristics," USAAVSCOM TM-87-A-3, Aug. 1987.

16. Whalley, M. S., and Carpenter, W. R., "A Piloted Simulation Investigation of Forward Flight Handling Qualities Requirements for Helicopter Air-to-Air Combat,” NASA TM-103919, May 1992.

17. Decker, W. M., Morris, P. M., and Williams, J. N., "A Piloted Simulation Investigation of Yaw Dynamics Requirements for Turreted Gun Use in Low-Level Helicopter Air Combat," 44th AHS Annual Forum, Washington, DC, June 1988.

18. Haworth, L. A., Atencio, A., Jr., Bivens, C., Shively, R., and Delgado, D., “Advanced Helicopter Cockpit And Control Configurations for Helicopter Combat Missions,” NASA-TM-100017, Dec. 1987.

19. Hoh, Roger H.; Heffley, Robert K.; and Mitchell, David G., "Development of Handling Qualities Criteria for Rotorcraft with Externally Slung Loads,” NASA CR-2006-213488, Oct. 2006.

20. Landis, K. H., and Glusman, S. I., "Development of ADOCS Controllers and Control laws, Volume 1: Executive Summary,” NASA-CR-177339, Mar. 1985. 
21. Glusman, S. I., Dabundo, C., and Landis, K. H., "Evaluation of ADOCS Demonstrator Handling Qualities; Advanced Digital Optical Control System,” AHS, 43rd Annual Forum, Saint Louis, MO, May 1987.

22. Whalley, M., and Howitt, J., "Optimizations of Partial Authority Automatic Flight Control Systems for Hover/Low-Speed Maneuvering in Degraded Visual Environments," Journal of the American Helicopter Society, Vol. 47, No. 2, Apr. 2002.

23. Key, D. L., and Heffley, R. K., Piloted Simulator Investigation of Techniques to Achieve Attitude Command Response with Limited Authority Servos, NASA-CR-2002-211391 USAAMCOM-TR-02-A003; Jan. 2002.

24. Mitchell, D. G., Aponso, B. L., Atencio, A., Key, D. L., and Hoh, R. H., "Increased Stabilization for UH60A Blackhawk Night Operations," USAAVSCOM TR-92-A-007, Nov. 1992.

25. Sahasrabudhe, V., Melkers, E., Faynberg, A., and Blanken, C. L., "Piloted Evaluation of Modernized Limited Authority Control Laws in the NASA-Ames Vertical Motion Simulator (VMS)," AHS $59^{\text {th }}$ Annual Forum, Phoenix, AZ, May 2003.

26. Irwin, J. G., Einthoven, P. G., Miller, D. G., and Blanken, C. L., "ADS-33E Predicted and Assigned LowSpeed Handling Qualities of the CH-47F with Digital AFCS,” AHS 63 ${ }^{\text {rd }}$ Annual Forum, Virginia Beach, VA, May 2007.

27. Schroeder, J. A., Watson, D. C., Tischler, M. B., and Eshow, M. M., "Identification and Simulation Evaluation of an AH-64 Helicopter Hover Math Model,” AIAA Paper 91-2877, AIAA Atmospheric Flight Mechanics Conference, New Orleans, LA, Aug. 1991.

28. Roscoe, M. F., and Wilkinson, C. H., "DIMSS - JSHIPs Modeling and Simulation Process for Ship/Helicopter Testing and Training," AIAA Modeling and Simulation Technologies Conference and Exhibit, Monterey, CA, Aug. 2002.

29. Paulk, C. H., Jr., Astill, D. L., and Donley, S. T., "Simulation and Evaluation of the SH-2F Helicopter in a Shipboard Environment Using the Interchangeable Cab System,” NASA-TM-84387, Aug. 1983.

30. Guerrero, L. M., and Corliss, L. D., "Initial Piloted Simulation Study of Geared Flap Control for Tilt-Wing V/STOL Aircraft,” NASA TM-103872, Oct. 1991.

31. Frost, C. R., Franklin, J. A., and Hardy, G. H., Evaluation of Flying Qualities and Guidance Displays for an Advanced Tilt-Wing STOL Transport Aircraft in Final Approach and Landing,” AIAA Paper 2002-6016, 2002 Biennial International Powered Lift Conference and Exhibit, Williamsburg, Virginia, Nov. 2002.

32. Corliss, L. D., Dunn, W. R.; and Morrison, M. A., "RSRA/X-Wing Flight Control System Development Lessons Learned,” AHS 45th Annual Forum, Boston, MA, May 1989.

33. Studebaker Fletcher, K., Decker, W. A., Matuska, D. C., Morris, P.M., and Smith, M. T, VMS Simulation of a Variable Diameter Tiltrotor,” AHS 53 ${ }^{\text {rd }}$ Annual Forum, Virginia Beach, VA, May 1992.

34. Mansur, M. H., and Schroeder, J. A., "An Investigation of the Ability to Recover from Transients Following Failures for Single-Pilot Rotorcraft,” NASA-TM-100078, May1988.

35. Hindson, W. S., Eshow, M. M., and Schroeder, J. A., "A Pilot Rating Scale for Evaluating Failure Transients in Electronic Flight Control Systems," AIAA Paper 90-2827, AIAA Atmospheric Flight Mechanics Conference, Portland, OR, Aug. 1990.

36. Clement, W.F., Cleveland, W.B., and Key, D.L., “Assessment of Simulation Fidelity Using Measurements of Piloting Technique in Flight, AGARD Conference Proceedings No 359, Monterey, CA, May 1984.

37. Atencio, Jr., A. "Fidelity Assessment of a UH-60A Simulation on the NASA Ames Vertical Motion Simulator," NASA TM 104016, USAATC Tech. Report 93-A-005, Sept. 1993.

38. Bray, R. S., "Visual and Motion Cuing in Helicopter Simulation,” NASA TM-86818, Sept. 1985.

39. McCauley, M.E., Hettinger, L.J., Sharkey, T.J., and Sinacori, J.B., "The Effects of Simulator VisualMotion Asynchrony on Simulator Induced Sickness,” AIAA Flight Simulation Technologies Conference and Exhibit, Dayton, OH, Sept. 1990.

40. Sharkey, T.J. and McCauley, M.E., "Does a Motion Base Prevent Simulator Sickness?” AIAA/AHS Flight Simulation Technologies Conference, Hilton Head, SC, Aug. 1992.

41. Mitchell, D.G. and Hart, D.C., "Effects of Simulator Motion and Visual Characteristics on Rotorcraft Handling Qualities," American Helicopter Society Conference on Piloting Vertical Flight Aircraft, San Francisco, CA, Jan. 1993.

42. Chung, W.W. and Schroeder, J.A., "Visual and Roll-Lateral Motion Cueing Synchronization Requirements for Motion-Based Flight Simulations" American Helicopter Society $53^{\text {rd }}$ Annual Forum Proceedings, Virginia Beach, VA, Apr. 1997. 
43. Mitchell, D.G., Hoh, R.H., Atencio Jr., A., and Key, D.L., "Ground Based Simulation Evaluation of the Effects of Time Delays and Motion on Rotorcraft Handling Qualities,” AVSCOM-TR-91-A-010, Aug. 1990.

44. Schroeder, J.A. "Simulation Motion Effect on Single Axis Compensatory Tracking," AIAA Flight Simulation Technologies Conference, Monterey, CA, 1993.

45. Schroeder, J.A., "Evaluation of Simulation Motion Fidelity Criteria in the Vertical and Directional Axes," Journal of the American Helicopter Society, Vol. 41, No. 2, Apr. 1996, pp. 44-57.

46. Schroeder, J.A. and Johnson, W.W., "Yaw Motion Cues in Helicopter Simulation," Paper No. 5, AGARD CP-577, Flight Simulation - Where are the Challenges?," Braunschweig, Germany, Apr. 1996.

47. Johnson, W. and Schroeder, J.A., "Visual-Motion Cueing in Altitude and Yaw Control," $38^{\text {th }}$ Annual Human Factors and Ergonomics Society Meeting, Nashville, TN, Oct. 1994.

48. Schroeder, J.A., Chung, W.W.Y., and Hess, R.A., "Evaluation of a Motion Fidelity Criterion with Visual Scene Changes,” Journal of Aircraft, Vol. 37, No. 4, July-August, 2000, pp. 580-587.

49. Zeyada, Y. and Hess, R.A., "Modeling Human Pilot Cue Utilization with Applications to Simulator Fidelity Assessment,” Journal of Aircraft, Vol. 37, No. 4, July-Aug., 2000, pp. 588-597.

50. Decker, W.A., Adam, C.F., and Gerdes, R.M., "Pilot Use of Simulator cues for Autorotation Landings," American Helicopter Society's 42 ${ }^{\text {nd }}$ Annual Forum, Washington, DC, June 1986.

51. Dearing, M.G., Schroeder, J.A., Sweet, B.T., and Kaiser, M.K., "Effects of Visual Texture, Grids, and Platform Motion on Unpowered Helicopter Landings," Paper 2001-4251, AIAA Modeling and Simulation Conference, Montreal, Canada, 2001.

52. Schroeder, J.A., Dearing, M.G., Sweet, B.T., Kaiser, M.K., and Atencio, Jr., A.A., "Runway Texture and Grid Pattern Effects on Rate-of-Descent Perception,” Paper 2001-4307, AIAA Modeling and Simulation Conference, Montreal, Canada, 2001.

53. Swenson, H. N., Paulk, C. H., Kilmer, R. L., and Kilmer, F. G., "Simulation Evaluation of Display/FLIR Concepts for Low-Altitude Terrain-Following Helicopter Operations,” NASA TM-86779, 1985.

54. Dorr, D. W., "Rotary Wing Aircraft Terrain Following/Terrain Avoidance System Development," NASA TM-88322, 1986.

55. Swenson, H. N., Zelenka, R. E., Hardy, G. H., and Dearing, M. G., "Simulation Evaluation of a LowAltitude Helicopter Flight Guidance System Adapted for a Helmet-Mounted Display,” NASA TM-103883, Feb. 1992.

56. Whalley, M. S., "A Comparison of Active Sidestick and Conventional Inceptors for Helicopter Flight Envelope Tactical Cueing,” AHS 56 ${ }^{\text {th }}$ Annual Forum, Virginia Beach, VA, May 2000.

57. Whalley, M. S., Keller, J., Buckanin, R., and Roos, J., "Helicopter Active Control Technology Demonstrator Program,” AHS 57 ${ }^{\text {th }}$ Annual Forum, Washington, DC, May 2001.

58. Iseler, L., Chen, R., Dearing, M., Decker, W., and Aiken, E. W.; "Simulator Investigation of Pilot Aids for Helicopter Terminal Area Operations with One Engine Inoperative,” AGARD Flight Vehicle Integration Panel Spring 1996 Symposium, Ottawa, Canada, May 1996.

59. Eshow, M. M., and Schroeder, J. A., "Improvements in Hover Display Dynamics for a Combat Helicopter,” Piloting Vertical Flight Aircraft: A Conference on Flying Qualities and Human Factors, San Francisco, CA, 1993.

60. Turpin, T. S., Dowell, S. R., and Szoboszlay, Z., "Comanche Helmet-Mounted Display Symbology Simulation; Final Report,” NASA CR 2006-212834, Oct. 2006.

61. DeMaio, J., and Rutkowski, M., "Evaluation of Helmet Mounted Display Alerting Symbology,” NASA TM 2000-209603, Sep. 2000.

62. Decker, W.A., "Piloted Simulator Investigations of a Civil Tilt-Rotor Aircraft on Steep Instrument Approaches," American Helicopter Society 48 ${ }^{\text {th }}$ Annual Forum, Washington, D.C., Jun. 1992.

63. Decker, W.A., Bray, R., Simmons, R.C., and Tucker, G.E., "Evaluation of Two Cockpit Display Concepts for Civil Tiltrotor Instrument Operations on Steep Approaches," American Helicopter Society Piloting Vertical Flight Aircraft: A Conference on Flying Qualities and Human Factors, San Francisco, CA, Jan. 1993.

64. Decker, W.A., "Handling Qualities Evaluation of XV-15 Noise Abatement Landing Approaches Using a Flight Simulator," American Helicopter Society $57^{\text {th }}$ Annual Forum, Washington, D.C., May 2001.

65. Hardy, G.H., "Pursuit Display Review and Extension to a Civil Tilt Rotor Flight Director," AIAA Paper 2002-4925, AIAA Guidance, Navigation, and Control Conference and Exhibit, Monterey, CA, Aug. 2002. 
66. Decker, W.A., and Hardy, G.H., "Civil Tiltrotor Transport Procedure and Requirement Development Using a Flight Simulator," AIAA Paper 2002-4530, AIAA Guidance, Navigation, and Control Conference and Exhibit, Monterey, CA, Aug. 2002.

67. Decker, W. A., Isleib, D., Major, and John, J., "A Simulator Investigation of Air-to-Air Combat Maneuvering for Tilt-Rotor Aircraft,” AHS National Technical Specialists’ Meeting on Tactical V/STOL, New Bern, NC, Sep. 1989. 